\title{
Investigating the in Vitro Thermal Stability and Conformational Flexibility of Estrogen Receptors as Potential Key Factors of Their in Vivo Activity
}

\author{
Adélaïde Le Grand, ${ }^{\dagger}$ Gwenaëlle André-Leroux, ${ }^{\ddagger}, \S$ Gaëlle Marteil, ${ }^{\|}$Hélène Duval, ${ }^{\dagger}$ Olivier Sire, ${ }^{\dagger}$ \\ and Véronique Le Tilly* ${ }^{\dagger}$
}

\begin{abstract}
†Laboratoire d’Ingénierie des Matériaux de Bretagne, Université de Bretagne-Sud, CER Yves Coppens, BP573, 56017 Vannes Cedex, France

${ }^{\ddagger}$ Institut National de la Recherche Agronomique, UR1404, Unité de Mathématiques et Informatiques Appliquées du Génome à l'Environnement, Domaine de Vilvert, 78352 Jouy-en-Josas, France

${ }^{\S}$ Institut Pasteur, Unité de Microbiologie Structurale, CNRS UMR 3528, 25 rue du Docteur Roux, 75724 Paris, France

"Instituto Gulbenkian de Ciëncia, Cell Cycle Regulation Lab, Rua da Quinta Grande, P-2780-156 Oreias, Portugal
\end{abstract}

Supporting Information

\begin{abstract}
Among hormone-inducible transcription factors, estrogen receptors (ERs) play important roles in tissue growth and differentiation, via either direct or indirect binding, in the nucleus, to specific DNA targets called estrogen responsive elements (EREs), or through nongenomic pathways. In humans, two estrogen receptor isoforms (hERs), designated $\mathrm{hER} \alpha$ and hER $\beta$, have been identified. These two hERs, encoded by genes located on distinct chromosomes, exhibit divergent tissue-specific functions and different subcellular distributions depending on their binding status, free or complexed to their cognate ligands. Because it is hypothesized that such distinct behaviors may arise from various conformational stabilities and flexibilities, the effect of salt concentration and temperature was studied on the free and estrogen-activated $\operatorname{hER} \alpha$ and $\operatorname{hER} \beta$. Our results show that the conformational stability of $\operatorname{hER} \beta$ is weakly modulated by salt concentration as opposed to $\mathrm{hER} \alpha$. In addition, we show that the estrogenbound hERs exhibit a more constrained structure than the unliganded ones and that their conformational flexibility is more affected by diethylstilbestrol binding than that of estradiol, 4-hydroxytamoxifen, or raloxifen. In line with these results, conformational analysis and computational docking were performed on $\mathrm{hER} \alpha$ and $\mathrm{hER} \beta$, which confer molecular support of a diethylstilbestrol-induced restrained flexibility as compared to other ligands. We found that $\operatorname{Trp} 383 \operatorname{in} \mathrm{hER} \alpha$ and $\operatorname{Trp} 335$ in hER $\beta$ can closely interact with the NR-box motif of the $\mathrm{H} 12$ helix and act as a gatekeeper of the agonist-bound versus antagonist-bound conformations. Altogether, our study contributes to an improved knowledge of the diverse physicochemical properties of fulllength hERs, which will help in our understanding of their distinct cellular roles in various cellular contexts.
\end{abstract}

\footnotetext{
$E_{\text {in }}^{\text {stons }}$ strogens, as primordial female steroid hormones, play important roles in the reproductive function via their action on organs such as breast, uterus, and prostate, and also in nonreproductive systems such as brain, bone, heart, and liver. ${ }^{1}$ The physiological functions controlled by estrogens are partly mediated by the estrogen receptor (ER), a hormone-inducible transcription factor, localized in and/or out of the nuclear compartment. In the nuclear compartment, ER positively or negatively regulates the expression of genes involved in tissue growth and differentiation, ${ }^{2,3}$ either by directly binding on specific DNA sequences located in the promoters of target genes or by interacting with other transcriptional factors in the nucleus. The extranuclear ER exerts rapid nongenomic actions that are usually associated with the activation of various protein kinase cascades. ${ }^{4}$ A dysregulation of ER signaling is associated with breast cancer.
}

The first human ER identified, designated $\operatorname{hER} \alpha$, was cloned from MCF-7 cells where it is overexpressed. ${ }^{5}$ A few years later, a second $\mathrm{ER}$, designated $\mathrm{hER} \beta$, was identified in different human organs. ${ }^{6,7}$ In humans, separate genes located on distinct chromosomes encode these two subtypes. ${ }^{8}$ These estrogen receptors exhibit specific tissue distributions, biological roles, ${ }^{9,10}$ and ligand affinities for various endogenous estrogens. ${ }^{11}$

The two hERs exhibit distinct subcellular distributions, while forming different protein transitory complexes and being involved in separate functional regulations mainly because they are involved in the regulation of a distinct set of genes. ${ }^{12,13}$

Received: January 11, 2015

Revised: $\quad$ May 23, 2015

Published: June 1, 2015 
Actually, $\operatorname{hER} \alpha$ is essentially localized in the nucleus ${ }^{14-16}$ whereas $\operatorname{hER} \beta$ is found in the nucleus and mitochondria. ${ }^{17}$ In mitochondria, $\mathrm{hER} \beta$ regulates the expression of proteins related to the oxidative phosphorylation. ${ }^{13}$

Human $\mathrm{ER} \alpha$ and $\mathrm{ER} \beta$ are 66 and $55 \mathrm{kDa}$ proteins, respectively, that share a modest $(47 \%)$ overall sequence identity. ${ }^{6}$ Human $\operatorname{ER} \beta$ exhibits a truncated sequence at the $\mathrm{N}$ and $\mathrm{C}$-terminal extremities. The most conserved domains are the $\mathrm{DBD}$ and LBD, DNA and ligand binding domains (also called C and E domains), with 94 and 59\% identity, respectively; these domains are also well-conserved among different species. The DBD is highly stabilized by two zinc fingers. The first one specifically interacts with oligonucleotide sequences called estrogen responsive elements (EREs), whereas the second one is responsible for dimerization of the DBD and the orientation of the first zinc finger. ${ }^{18}$ The LBD, comprising a hormone binding site, a dimerization interface, and a coregulator interaction function, exhibits a helical structure. Its $11 \alpha$-helices are organized in a three-layer sandwich structure with $\mathrm{H} 4, \mathrm{H} 6, \mathrm{H} 8$, and $\mathrm{H} 9$ forming one layer flanked on one side by $\mathrm{H} 1$ and $\mathrm{H} 3$ and on the other side by $\mathrm{H} 7, \mathrm{H} 10$, and $\mathrm{H} 11$. The H12 helix undergoes a differential repositioning upon ligand binding, adopting a unique conformation compatible with coactivator binding in both agonist-bound ER isotypes. ${ }^{19,20}$ The other domains, A/B, D, and F, share 17, 30 , and $18 \%$ identity, respectively, and are generally considered to be flexible.

The classical model of transactivation of ER requires not only estrogen binding, releasing of ERs from inactive complexes, dimerization, and DNA binding processes but also translocation toward the nuclear compartment and transcription activation processes. Actually, estrogen binding initiates the release of ER from inactive complexes, ${ }^{21}$ which consequently induces its dimerization, translocation to the nucleus, and its sequencespecific binding to ERE. ${ }^{14-16}$ Once bound to its specific target sequence, ER dimer interacts with a series of coregulators. ${ }^{22-24}$ These ER-coregulator complexes affect the chromatin structure and modulate the RNA polymerase II recruitment and activity. These partners may bind to the ER N-terminal end or to the $\mathrm{LBD}$ region; ${ }^{22,23}$ thus, the transcription activation function is hormone-independent (AF-1) or hormone-dependent (AF-2). ${ }^{25}$

Despite the numerous structural data available about human ERs, obtained by using either the full-length receptor or partial constructs, little information has been gathered concerning the thermodynamic parameters of the molecular interactions responsible for the stabilization of the functionally effective conformations. The knowledge of these energetic features is essential for understanding their distinct cellular behaviors. Thus, our study, while mainly focused on the thermodynamic stability differences between the two hERs and the contribution of the electrostatic network to their respective flexibility and functionality, also takes into account the molecular features that could explain these discrepancies. This study shows that hER $\alpha$ and $\operatorname{hER} \beta$ distinctly respond to charge screening. In other words, the compromise between conformational stability and flexibility varies from one form to the other; consequently, this likely alters their binding status, i.e., their respective set of interactions with other partners such as coregulators, and makes them distinctly sensitive to any ionic strength variation. Conformational analysis of yet unsolved complexes combined with our in silico docking studies substantiates these differences and is reported here. Hence, a better knowledge of the physicochemical properties of both human ERs combined with structural highlights might allow a better understanding of the role of each hER and, in the future, may be useful for the development of new drugs designed to prevent or cure breast cancer.

\section{EXPERIMENTAL PROCEDURES}

Reagents and Buffer Solutions. All reagents were obtained from Sigma (St. Louis, MO) or Carlo Erba Reactifs (Val de Reuil, France) unless indicated otherwise. The steroid compounds used in this study, E2, DES, 4-OHT, and RAL, were solubilized in ethanol, except for RAL, which was solubilized in DMSO. The steroid stock solution concentration was $10^{-5} \mathrm{M}$. The buffer solution was $10 \mathrm{mM}$ Tris- $\mathrm{HCl}$ with $\mathrm{KCl}$ at various concentrations $(80,140$, or $200 \mathrm{mM})(\mathrm{pH} 7.5)$, $0.1 \mathrm{mM}$ EDTA, $1 \mathrm{mM}$ DTT, and 10\% glycerol.

Recombinant Proteins. Full-length purified recombinant human $\operatorname{ER} \alpha$ and $\operatorname{ER} \beta$ ( $\operatorname{rhER} \alpha$ and $\operatorname{rhER} \beta$, respectively), baculovirus-expressed, were purchased from Invitrogen (Cergy-Pontoise, France) and stored at $-80{ }^{\circ} \mathrm{C}$. The protein concentrations of $\operatorname{ER} \alpha$ and $\operatorname{ER} \beta$ were $2.6 \times 10^{-6}$ and $4.5 \times 10^{-6}$ $\mathrm{M}$, respectively. The purity of ER samples was checked by the standard method using sodium dodecyl sulfate-polyacrylamide gel electrophoresis followed by Coomassie Brilliant Blue R250 staining. The possible post-translational modifications (PTMs) of both commercial ERs have been checked by using two kits following the manufacturer's recommendations: Pro-Q Diamond phosphoprotein gel stain and Pro-Q Emerald 488 glycoprotein Gel and blot stain kit (Invitrogen). One hour before every experiment, each protein sample was thawed and diluted to $7.5 \times 10^{-7} \mathrm{M}$ in assay buffer. This pre-equilibration time is required for protein stabilization. Protein samples, buffers, and other solutions were kept on ice for the duration of the experiments.

Fluorescein-Labeled Oligonucleotides. Doublestranded oligonucleotide solutions were prepared from two $21 \mathrm{bp}$ complementary oligonucleotidic sequences that were coupled to fluorescein at the $5^{\prime}$ end. These oligonucleotides were synthesized, purified, and adjusted to $100 \mu \mathrm{M}$ by Proligo (Paris, France). The sequences of the sense strand of palindromic consensus $\mathrm{ERE}\left(\mathrm{ERE}_{\mathrm{cs}}\right)$, natural rainbow trout ERE ( $r$ tvtgERE), and nonspecific oligonucleotide (OLIns) are 5'-GTCAGGTCACAGTGACCTGAT-3', 5'-AGTGGGGCAGGTTAACCTAAC-3', and 5'-CCCACGTAAAACTGACCATCC- $3^{\prime}$, respectively. The $r t v t g E R E$ degenerated sequence was previously identified in our laboratory in the promoter region of Oncorhynchus mykiss vitellogenin genes. ${ }^{26}$

The duplexes were formed by diluting each oligonucleotide in assay buffer [ $10 \mathrm{mM}$ Tris- $\mathrm{HCl}, 80 \mathrm{mM} \mathrm{KCl}, 0.1 \mathrm{mM}$ EDTA, $1 \mathrm{mM}$ DTT, and $10 \%$ glycerol $(\mathrm{pH} 7.5)]$ to reach a final oligonucleotide concentration of $1 \mu \mathrm{M}$. Then, both complementary oligonucleotides were mixed and heated to $85{ }^{\circ} \mathrm{C}$ for $10 \mathrm{~min}$ and slowly cooled to $4{ }^{\circ} \mathrm{C}$.

Steady-State Fluorescence Experiments. All experiments were conducted with recombinant human ERs at $10 \pm$ $2{ }^{\circ} \mathrm{C}$ except for the thermal stability experiments. Steady-state fluorescence emission was measured by using an SLM8100 spectrofluorimeter. Spectra and anisotropy values were corrected by subtracting the contribution of the buffer solution to the signal. All experiments were repeated independently at least three times.

ER-ERE Equilibrium Constants. To determine the effect of the salt concentration on the complexes formed between 
$\operatorname{rhER} \alpha$ (or $\operatorname{rhER} \beta$ ) and different ERE sequences, the fluorescence anisotropy values of fluorescein covalently bound to oligonucleotides were measured as a function of rhER concentration.

Fluorescein-labeled oligonucleotide fluorescence anisotropy values were monitored with an excitation wavelength of $480 \mathrm{~nm}$ and a bandwidth for excitation of $2 \mathrm{~nm}$; the fluorescence emission intensities were collected through a 515 cutoff Oriel filter, which removes the excitation light scattering. The emission anisotropy, $A$, was calculated according to

$$
A=\frac{F_{\mathrm{VV}}-F_{\mathrm{VH}}\left(\frac{F_{\mathrm{HV}}}{F_{\mathrm{HH}}}\right)}{F_{\mathrm{VV}}+2 F_{\mathrm{VH}}\left(\frac{F_{\mathrm{HV}}}{F_{\mathrm{HH}}}\right)}
$$

where $F_{12}$ features the emission fluorescence intensity with subscripts 1 and 2 indicating the vertical and horizontal position of the excitation and emission polarizers, respectively. Fluorescence anisotropy measurements were taken with an integration time of $5 \mathrm{~s}$ on each emission intensity component.

For rhER-oligonucleotide binding titration experiments, the oligonucleotide concentration was kept constant at $10^{-9} \mathrm{M}$ and the protein concentration varied between $2 \times 10^{-10}$ and $3 \times$ $10^{-8} \mathrm{M}$. Prior to the collection of anisotropy values, the sample (oligonucleotide plus protein) was incubated for $10 \mathrm{~min}$ to allow protein-oligonucleotide complexation. These binding titration experiments were performed in the presence of 80 , 140 , or $200 \mathrm{mM} \mathrm{KCl}$.

The dissociation constant, $K_{\mathrm{D}}$, of the rhER-ERE equilibrium is recovered by fitting the binding titration curve to the equations below assuming that, within the protein concentration range used, only one equilibrium is observed:

$$
A=\frac{K_{\mathrm{D}} A_{\mathrm{DNA}^{*}}}{[\mathrm{rhER}]+K_{\mathrm{D}}}+\frac{[\mathrm{rhER}] A_{\mathrm{DNA}^{*}-\mathrm{rhER}}}{[\mathrm{rhER}]+K_{\mathrm{D}}}
$$

with $A_{\mathrm{DNA}^{*}}$ and $A_{\mathrm{DNA}^{*}-\mathrm{rhER}}$ are the anisotropy values of fluorescein-labeled oligonucleotide and fluorescein-labeled oligonucleotide covalently bound to rhER, respectively, and [rhER] is the concentration of free rhER.

Because the concentration of oligonucleotide is slightly lower than the $K_{\mathrm{D}}$ value in some experiments, the equation used for data fitting and recovering the $K_{\mathrm{D}}$ value is

$$
\begin{aligned}
& A=\left[1-\left(\frac{\left(\left[D N A^{*}\right]_{t}+[r h E R]_{t}+K_{D}\right)-\sqrt{\left(\left[D N A^{*}\right]_{t}+[r h E R]_{t}+K_{D}\right)^{2}-4[r h E R]_{t}\left[D N A^{*}\right]_{t}}}{2\left[D N A^{*}\right]_{t}}\right)\right] A_{D N A^{*}} \\
& +\left[\frac{\left(\left[D N A^{*}\right]_{t}+[r h E R]_{t}+K_{D}\right)-\sqrt{\left(\left[D N A^{*}\right]_{t}+[r h E R]_{t}+K_{D}\right)^{2}-4[r h E R]_{,}\left[D N A^{*}\right]_{t}}}{2\left[D N A^{*}\right]_{t}}\right] A_{D N A^{*}-\text { hER }}
\end{aligned}
$$

Values of the dissociation equilibrium constant $\left(K_{\mathrm{D}}\right)$ were obtained by nonlinear least-squares curve fitting using the commercial Peakfit software.

rhER Flexibility. To probe hER relative flexibility, as free or complexed forms, the effect of salt concentration and ligand binding was investigated through the monitoring of the dynamic accessibility of tryptophanyl residues by fluorescence quenching experiments.

Tryptophan fluorescence quenching experiments were conducted by using acrylamide, which is known to be an efficient quencher of tryptophanyl fluorescence. ${ }^{27,28}$ Fluorescence spectra were recorded with bandwidths fitted for excitation and emission resolution of 4 and $2 \mathrm{~nm}$, respectively. The excitation wavelength was $290 \mathrm{~nm}$ to ensure that the measured fluorescence was due to the sole tryptophanyl residues. Fluorescence emission intensity was collected with an integration time of $1 \mathrm{~s}$, between 300 and $430 \mathrm{~nm}$. Each displayed spectrum is the average of four acquisitions.

These experiments were conducted at $5 \times 10^{-8} \mathrm{M}$ rhERs and various acrylamide concentrations from 0 to $0.17 \mathrm{M}$. Stock acrylamide solutions ( $2 \mathrm{M})$ were obtained by dissolving acrylamide (Sigma) in assay buffer. Experiments with ligands were performed at $140 \mathrm{mM} \mathrm{KCl}$ in the presence of E2, DES, 4OHT, or RAL at a final concentration of $10^{-7} \mathrm{M}$ to achieve 99\% rhER complexation. ${ }^{11}$

The quenching of fluorescence of fluorophore residues in proteins can occur in two ways: (i) static quenching arising from the formation of a complex between the fluorophore and the quencher before excitation and (ii) dynamic quenching resulting from encounters of fluorophore and quencher molecules during the excited-state lifetime. When both occur, the quenching process can be analyzed according to the modified Stern-Volmer equation:

$$
\frac{F_{0}}{F}=\left(1+K_{\mathrm{SV}}[\mathrm{Q}]\right)\left(1+K_{\mathrm{a}}[\mathrm{Q}]\right)
$$

where $F_{0}$ and $F$ are the fluorescence intensity in the absence and presence of the quencher $\mathrm{Q}$ respectively, and $K_{\mathrm{SV}}$ and $K_{\mathrm{a}}$ are the collisional and static quenching constants, respectively. If a single process is operating or dominating, the plot of $F_{0} / F$ versus [Q] is linear; if both processes occur, the plot of $F_{0} / F$ versus $[\mathrm{Q}]$ exhibits an upward curvature.

For proteins having several fluorophore residues, the quenching data can be described by Lehrer's equation:

$$
\frac{F_{0}}{\Delta F}=\frac{1}{f_{\mathrm{a}} K_{\mathrm{SV}}[\mathrm{Q}]}+\frac{1}{f_{\mathrm{a}}}
$$

where $\Delta F=F_{0}-F$ is the fluorescence intensity decrease observed at quencher concentration $\left[\mathrm{Q}, f_{\mathrm{a}}\right.$ the fractional maximum of the accessible fluorophores, and $K$ the quenching constant. For dynamic quenching, the constant $K_{\mathrm{SV}}$ is equal to the product $k_{\mathrm{q}}\langle\tau\rangle$, where $k_{\mathrm{q}}$ is the bimolecular collisional rate constant and $\langle\tau\rangle$ the average fluorescence lifetime in the absence of quencher. The fraction of the accessible fluorophores was determined from the $y$-intercept of the plot of $F_{0} / \Delta F$ versus $1 /[\mathrm{Q}]$ and the apparent quenching constant from the ratio of the $y$-intercept to the slope.

rhER Thermal Stability. To measure the effect of salt concentration on the stability of the two human estrogen receptor isoforms, the fluorescence intensity of tryptophanyl residues in rhERs was monitored as a function of temperature. The fluorescence intensities were measured by exciting the protein sample at $290 \mathrm{~nm}$ and collecting the emission at 338 $\mathrm{nm}$. These experiments were performed by increasing the temperature from 5 to $55{ }^{\circ} \mathrm{C}$ with a $3{ }^{\circ} \mathrm{C}$ step, and the signal was recorded $10 \mathrm{~min}$ after the temperature had been increased. To obtain the apparent $T_{\mathrm{M}}$ and the enthalpy change $(\Delta r H)$ of unfolding of hERs, the data were fit by using a two-state $(\mathrm{N} \stackrel{K}{\leftrightarrow}$ D) or a three-state $\left(\mathrm{N} \stackrel{K_{1}}{\leftrightarrow} \mathrm{I} \stackrel{K_{2}}{\leftrightarrow} \mathrm{D}\right)$ model according to the following mathematical equations:

$$
I_{\text {obs }}=\frac{1}{1+K}\left(I_{\mathrm{N}}+K I_{\mathrm{D}}\right), \text { where } K=\mathrm{e}^{\frac{\Delta r H}{R T}\left(\frac{T}{T_{\mathrm{M}_{1}}}-1\right)}
$$




$$
I_{\text {obs }}=\frac{1}{1+K_{1}+K_{1} K_{2}}\left(I_{\mathrm{N}}+K_{1} I_{\mathrm{I}}+K_{1} K_{2} I_{\mathrm{D}}\right)
$$

with

$$
K_{1}=\mathrm{e}^{\frac{\Delta r H_{1}}{R T}\left(\frac{T}{T_{M_{1}}}-1\right)}
$$

and

$$
K_{2}=\mathrm{e}^{\frac{\Delta r H_{2}}{R T}\left(\frac{T}{T_{M_{2}}}-1\right)}
$$

where $I_{\mathrm{N}}, I_{\mathrm{V}}$, and $I_{\mathrm{D}}$ are the fluorescence intensities of the native, intermediary, and denatured hER forms, respectively. $K$ and $\Delta r H$ are the protein unfolding equilibrium constant and the apparent van't Hoff enthalpy of unfolding, respectively. $T_{M}$ is the temperature at the midpoint of the unfolding transition. $I_{\mathrm{N}}$, $I_{\mathrm{I}}, I_{\mathrm{D}}, \Delta r H$, and $T_{\mathrm{M}}$ values were recovered from nonlinear leastsquares curve fitting using the commercial Peakfit software. The displayed values of $T_{\mathrm{M}}$ and $\Delta r H$ are the apparent values because of the nonreversibility of the observed unfolding process.

Time-Resolved Fluorescence Measurements. Tryptophan fluorescence lifetime measurements were taken with a Fluoromax-3 fluorescence spectrophotometer from HoribaJobin-Yvon (Longjumeau, France). An electroluminescent diode with a pulse width of 800 ps was used for excitation, and a Hamamatsu model R928 photomultiplier was used to detect the fluorescence. Samples were excited at $280 \mathrm{~nm}$, and emission intensities were recorded at $338 \mathrm{~nm}$. Slit widths of the excitation and emission monochromators were 15 and $10 \mathrm{~nm}$, respectively. The decay curves were analyzed by threeexponential iterative fitting program Daf6 (Horiba Scientific). The mean lifetime was calculated from

$$
\langle\tau\rangle=\frac{\Sigma_{i} \alpha_{i} \tau_{i}^{2}}{\Sigma_{i} \alpha_{i} \tau_{i}}
$$

where $\alpha_{i}$ is the molar fraction of component $i$ and $\tau_{i}$ is the lifetime of each discrete exponential component.

Molecular Modeling Docking. The crystal coordinates of the human ER $\alpha$ LBD in complex with E2 [Protein Data Bank (PDB) 1g50], ${ }^{29}$ DES (PDB entry 3erd), ${ }^{30}$ 4-OHT (PDB entry 3ert), ${ }^{30,31}$ and RAL (PDB entry lerr) ${ }^{32}$ were retrieved from the PDB. The interaction energy between $\operatorname{hER} \alpha$ LBD and ligands, agonist, or SERM was evaluated for each crystal complex with the CHARMm force field ${ }^{33}$ and "smart minimizer" module, implemented in DiscoveryStudio (Accelrys Software). Similarly, the crystal coordinates of the human $\operatorname{ER~} \beta$ LBD in complex with E2 (PDB entry 3oll $)^{20}$ and 4-OHT (PDB entry $\left.2 \mathrm{fsz}\right)^{34}$ were retrieved from the $\mathrm{PDB}$, and the interaction energy was computed within the same protocol. For missing DES-ER $\beta$ and RAL-ER $\beta$ complexes, the coordinates of human agonistbound DES-ER $\alpha$ and RAL-ER $\alpha$ complexes were superimposed onto agonist-bound E2-ER $\beta$ and SERM-bound 4OHT-ER $\beta$ complexes, respectively, using the SSM (Secondary Structure Matching) module implemented in Coot version 0.7.2. ${ }^{35}$ That superimposition gave accurate starting positions of DES and RAL in the ER $\beta$ LBD that were subsequently minimized using the CHARMm force field and "smart minimizer" protocol, with no constraint on ligand or side chains. Similarly, the interaction energy was computed. All crystal and in silico complexes were then visually inspected using Pymol (The PyMOL Molecular Graphics System, version 1.5.0.2, Schrödinger, LLC).

\section{RESULTS}

We have previously shown that the interaction between $\operatorname{rhER} \alpha$ and its ERE targets depends on the conformational flexibility of rhER $\alpha{ }^{36}$ This work aims to characterize the factors that significantly contribute to the conformational stability of the two hER isoforms and, consequently, to their biological function. To this end, we used commercial rhERs, expressed in insect cells, which are both phosphorylated and unglycosylated (Figure S1 of the Supporting Information). To determine how the electrostatic network of human ERs, free and estrogenbound forms, modulates the conformational stability and flexibility, the effect of salt concentration was investigated at $\mathrm{pH}$ 7.5. Upon analysis of hER amino acid sequences, $\operatorname{hER} \beta$ $(+12.7)$ appears to be more positively than $\mathrm{hER} \alpha$ at this $\mathrm{pH}$ value $(+4.5)$.

The Interaction between $\operatorname{rhER} \beta$ and EREs Is Ruled by Electrostatic Interactions. The ability of $\operatorname{rhER} \beta$ to interact with different ERE sequences has been monitored by using the fluorescence anisotropy methodology. This technique allows evaluation, in solution, of the impact of physicochemical parameters on the interaction between molecules. ${ }^{37-40}$ For this study, binding of $\operatorname{rhER} \beta$ to two oligonucleotide target sequences, consensus and imperfect EREs, was conducted with a $21 \mathrm{bp}$ double-stranded oligonucleotide labeled at the $5^{\prime}$ end with fluorescein. The ERE consensus, $\mathrm{ERE}_{\mathrm{cs}}$, bears the palindromic AGGTCA half-site separated by $3 \mathrm{bp}$ from the other site. The imperfect ERE, rtvtgERE, has been identified in the intergenic region of the rainbow trout vitellogenin gene.

In this study, the effect of $\mathrm{KCl}$ concentration on the interaction between $\operatorname{rhER} \beta$ and both ERE sequences has been investigated. The fluorescein-labeled EREs were titrated with $\operatorname{rhER} \beta$ until the anisotropy value reached a plateau, which reflects the saturation of the binding sites. The resulting EREER binding curve was fitted with eq 3 to determine the $K_{\mathrm{D}}$ values. Figure 1 displays the effect of $\mathrm{KCl}$ concentration on the

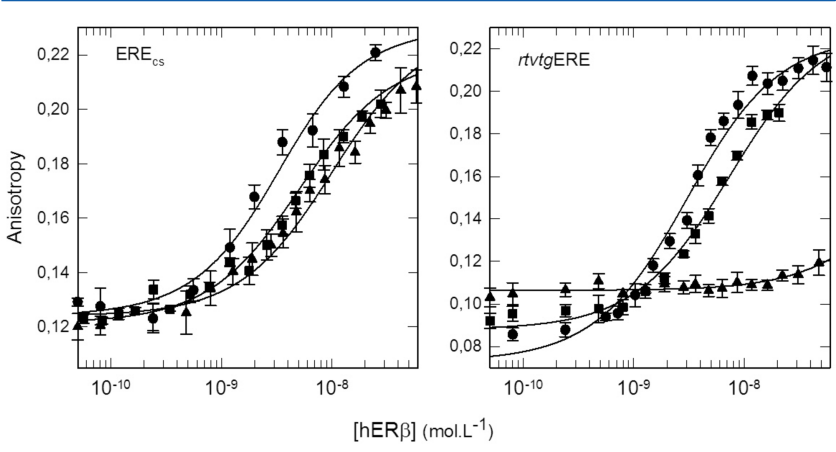

Figure 1. Fluorescence anisotropy profiles of fluorescein-labeled ERE upon $\operatorname{rhER} \beta$ binding. Titrations of $1 \mathrm{nM}$ labeled EREcs and rtvtgERE are performed at various $\mathrm{KCl}$ concentrations: $80(\boldsymbol{)}), 140(\boldsymbol{\square})$, and $200 \mathrm{mM} \mathrm{KCl}(\boldsymbol{\Delta})$. Experimental conditions: $10 \mathrm{mM}$ Tris- $\mathrm{HCl}$ buffer (pH 7.5), $10 \%$ glycerol, $0.1 \mathrm{mM}$ EDTA, and $1 \mathrm{mM} \mathrm{DTT}$ at $10{ }^{\circ} \mathrm{C}$. The lines through the data result from data fitting using a singleequilibrium model (eq 3 ).

interaction between $\operatorname{rhER} \beta$ and $\mathrm{ERE}_{\mathrm{cs}}$. The binding curve is displaced toward the high protein concentrations as the $\mathrm{KCl}$ concentration increases, which indicates that the affinity of the complex decreases at high salt concentrations. Because the electrostatic interactions are weakened by the salt counterions, this result shows that the $\operatorname{rhER} \beta-\mathrm{ERE}_{\mathrm{cs}}$ interaction is essentially ruled by electrostatic forces. A similar result is 
observed for the interaction of $\operatorname{rhER} \beta$ with an imperfect ERE (Figure 1). As expected, $\operatorname{rhER} \beta$ exhibits a lower affinity for $r t v t g E R E$ than for $\mathrm{ERE}_{\mathrm{cs}}$. Furthermore, the salt effect is more pronounced for the $\operatorname{rhER} \beta-r t v \operatorname{tg} E R E$ complex than for the $\operatorname{rhER} \beta-\mathrm{ERE}_{\mathrm{cs}}$ complex. This result indicates that the nature and/or number of electrostatic interactions stabilizing the two complexes differs. Table 1 displays the different recovered $K_{D}$

Table 1. $K_{\mathrm{D}}$ Values for rhER-ERE Interactions

\begin{tabular}{cllcc} 
& & \multicolumn{3}{c}{$K_{\mathrm{D}}\left(\times 10^{-9} \mathrm{~mol} \mathrm{~L}^{-1}\right)$} \\
\cline { 3 - 5 } $\operatorname{rhER} \alpha$ & & $80 \mathrm{mM} \mathrm{KCl}$ & $140 \mathrm{mM} \mathrm{KCl}$ & $200 \mathrm{mM} \mathrm{KCl}$ \\
& ERE $_{\mathrm{cs}}$ & $2.0 \pm 0.5^{a}$ & $3.0 \pm 0.4^{b}$ & $4.8 \pm 0.7^{a}$ \\
& $r$ tvtgERE & $2.5 \pm 0.8^{a}$ & $6.2 \pm 0.3^{a}$ & $>40^{a}$ \\
$\operatorname{rhER} \beta$ & ERE $_{\mathrm{cs}}$ & $3.3 \pm 0.7$ & $4.6 \pm 1.2$ & $9.3 \pm 0.7$ \\
& rtvtgERE & $3.8 \pm 0.5$ & $7.1 \pm 1.3$ & $>50$
\end{tabular}

${ }^{a}$ The $K_{\mathrm{D}}$ values of hER $\alpha$ in the presence of 80 and $200 \mathrm{mM} \mathrm{KCl}$ were previously reported. ${ }^{27} b^{b}$ The $K_{\mathrm{D}}$ value of hER $\alpha$ in the presence of 140 $\mathrm{mM} \mathrm{KCl}$ was previously reported. ${ }^{26}$

values for both receptors. Whatever the ERE sequence and whatever the salt concentration, our results show that $\operatorname{rhER} \alpha$ exhibits an affinity for ERE sequences higher than that of $\operatorname{rhER} \beta$. The modulation of complexes affinities by salts is slightly more pronounced for $\operatorname{rhER} \beta$ than for $\operatorname{rhER} \alpha$.

rhER $\alpha$ and $\operatorname{rhER} \boldsymbol{\beta}$ Electrostatic Networks. It is generally accepted that an increased thermal stability is due to an increased number of electrostatic interactions (ion pairs, $\mathrm{H}$ bonds, etc.). ${ }^{41}$ Thus, temperature-induced unfolding experiments of rhERs have been undertaken to report the relevance of the electrostatic network within these two isoforms. This was achieved by collecting the fluorescence emission of tryptophanyl residues after heating the protein samples from 5 to 55 ${ }^{\circ} \mathrm{C}$. Following an increase in temperature, the total intensity decreases (Figure 2A). This temperature-induced fluorescence
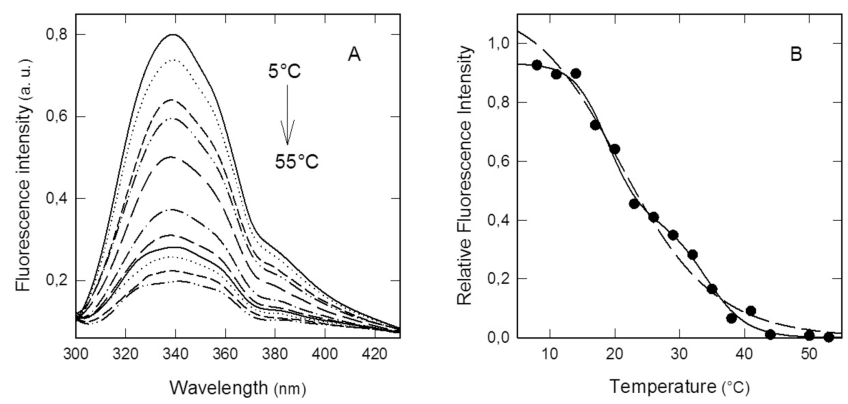

Figure 2. Thermal unfolding of $\operatorname{rhER} \beta$. (A) Fluorescence emission spectra of recombinant human $\operatorname{ER} \beta$ as a function of temperature $\left(\lambda_{\text {exc }}\right.$ $=290 \mathrm{~nm}$ ). (B) Relative fluorescence intensity of $\operatorname{rhER} \beta$ in the presence of $200 \mathrm{mM} \mathrm{KCl}\left(\lambda_{\mathrm{em}}=338 \mathrm{~nm}\right)$. The data were fitted according to two models (eq 7): a two-state model (---) and a three-state model $(-)$. The data are best fitted with a three-state model as shown from the $R^{2}$ value $(0.99550)$ compared to the twostate model $\left(R^{2}=0.99050\right)$ and from a less structured residual.

emission decrease has been analyzed according to a two-state model and a three-state model. Whatever the isoform, the best fit is obtained with a three-state model (Figure 2B and Figure S2 of the Supporting Information). As shown in Figure 3, this temperature-driven biphasic unfolding pattern is observed for $\operatorname{rhER} \alpha$ and $\operatorname{rhER} \beta$ regardless of the $\mathrm{KCl}$ concentration. The thermodynamic parameters of hER unfolding have been

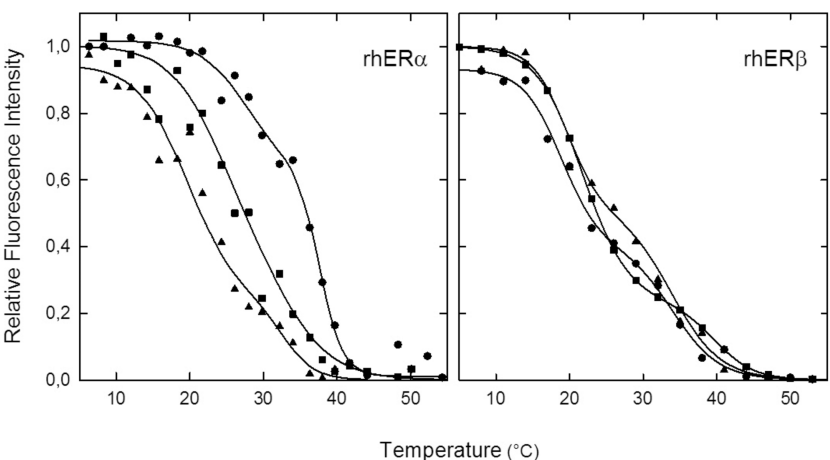

Figure 3. Thermal unfolding curve of rhERs as a function of salt concentration. The Trp relative fluorescence intensity was monitored at $338 \mathrm{~nm}$ as a function of temperature $\left(\mathrm{pH} 7.5 ; \lambda_{\text {exc }}=290 \mathrm{~nm}\right) . \mathrm{KCl}$ concentrations were $80(\mathbf{O}), 140(\boldsymbol{\square})$, and $200 \mathrm{mM}(\boldsymbol{\Delta})$. The data were fitted according to a three-state model.

recovered by curve fitting according to a three-state model (Table 2). As the thermal unfolding of hERs is not reversible under our experimental conditions (data not shown), the thermodynamic parameters determined are apparent values. The $\operatorname{rhER} \alpha$ transition midpoints of thermal denaturation, $T_{\mathrm{M}}$, decrease as $\mathrm{KCl}$ concentration increases, indicating a reduced thermal stability of $\operatorname{rhER} \alpha$ in the presence of high salt concentrations. This result is in agreement with the fact that the higher the salt concentration, the less numerous the electrostatic interactions and subsequently the less stable the protein. For $\operatorname{rhER} \beta$, the thermal denaturation is weakly altered by $\mathrm{KCl}$ concentration within the range investigated here. These data indicate that the thermal unfolding process of $\operatorname{rhER} \alpha$ is highly sensitive to salt concentration compared to that of $\operatorname{rhER} \beta$. Furthermore, regardless of the salt concentration, $\operatorname{rhER} \alpha T_{\mathrm{M}}$ values are greater than that of $\operatorname{rhER} \beta$, which indicates that the overall stability of $\operatorname{rhER} \alpha$ is higher than that of $\operatorname{rhER} \beta$. These biophysical data are in agreement with the crystal structures of the E2-hER $\alpha^{19,29}$ and E2-hER $\beta^{20}$ LBDs, which both display numerous and highly accessible positively charged Arg and Lys and negatively charged Asp and Glu residues (Figure S3 of the Supporting Information). Moreover, both isotypes form LBD homodimers, which are highly stabilized by electrostatic interactions involving helices H10 and $\mathrm{H} 11$ at their interface (Figure S3 of the Supporting Information). One can hypothesize that a high salt concentration could screen the electrostatic interactions, notably the ones located at the dimer interface, thus destabilizing the dimer and modifying the positioning of helices $\mathrm{H} 10$ and $\mathrm{H} 11$ and leading to enhanced instability.

Electrostatic Interactions Contribute to the rhER Conformational Flexibility. On the basis of sequence analysis (Figure 4A), hER $\alpha$ contains five tryptophanyl residues: one residue located in the DBD (C domain), another in the hinge region ( $\mathrm{D}$ domain), and the others in the $\mathrm{LBD}$ or $\mathrm{E}$ domain (Figure 4B, left). Human ER $\beta$ contains seven tryptophanyl residues: four in the LBD [three at equivalent positions of hER $\alpha$ (see Figure 4B, right)], another in the DBD (at equivalent position of $\mathrm{hER} \alpha$ ), and two in the N-terminal region of the protein.

The ER flexibility was assessed by the dynamic accessibility of protein tryptophan to the acrylamide. This neutral quencher is able to diffuse inside the hydrophobic core of the proteins, allowing hence collision with the tryptophanyl residues. The 
Table 2. Effect of $\mathrm{KCl}$ Concentration on the Thermal Unfolding of rhERs at $\mathrm{pH} 7.5$ Using van't Hoff Analysis ${ }^{a}$

\begin{tabular}{|c|c|c|c|c|c|c|}
\hline \multirow[b]{2}{*}[\mathrm{KCl}]{$(\mathrm{mM})$} & \multicolumn{3}{|c|}{$\operatorname{rhER} \alpha$} & \multicolumn{3}{|c|}{$\operatorname{rhER} \beta$} \\
\hline & $T_{\mathrm{M}}\left({ }^{\circ} \mathrm{C}\right)$ & $\Delta r H\left(\mathrm{~kJ} \mathrm{~mol}{ }^{-1} \mathrm{~K}^{-1}\right)$ & $\Delta r S(\mathrm{~kJ} / \mathrm{mol})$ & $T_{\mathrm{M}}\left({ }^{\circ} \mathrm{C}\right)$ & $\Delta r H\left(\mathrm{~kJ} \mathrm{~mol}{ }^{-1} \mathrm{~K}^{-1}\right)$ & $\Delta r S(\mathrm{~kJ} / \mathrm{mol})$ \\
\hline \multirow[t]{2}{*}{80} & $27.9 \pm 2.0$ & $233 \pm 127$ & 0.77 & $18.7 \pm 0.8$ & $200 \pm 84$ & 0.69 \\
\hline & $37.7 \pm 0.8$ & $520 \pm 179$ & 1.67 & $34.9 \pm 1.5$ & $270 \pm 45$ & 0.88 \\
\hline \multirow[t]{2}{*}{140} & $24.2 \pm 0.5$ & $197 \pm 97$ & 0.66 & $21.8 \pm 0.2$ & $231 \pm 12$ & 0.78 \\
\hline & $33.5 \pm 0.8$ & $214 \pm 108$ & 0.70 & $39.9 \pm 0.7$ & $310 \pm 61$ & 0.99 \\
\hline \multirow[t]{2}{*}{200} & $19.9 \pm 0.7$ & $208 \pm 38$ & 0.71 & $19.6 \pm 1.1$ & $299 \pm 81$ & 1.02 \\
\hline & $33.0 \pm 1.2$ & $365 \pm 110$ & 1.19 & $34.1 \pm 0.7$ & $244 \pm 50$ & 0.79 \\
\hline
\end{tabular}

${ }^{a}$ Because the unfolding is not reversible, the determined $T_{\mathrm{M}}$ and $\Delta r H$ are apparent values. The recovered values derive from data fitting by using a three-state model. $\Delta r S$ has been calculated by using $\Delta r S=(\Delta r H) / T_{\mathrm{M}}$. Experimental conditions are as follows: $\lambda_{\mathrm{exc}}=290 \mathrm{~nm}$, and $\lambda_{\mathrm{em}}=338 \mathrm{~nm}$.

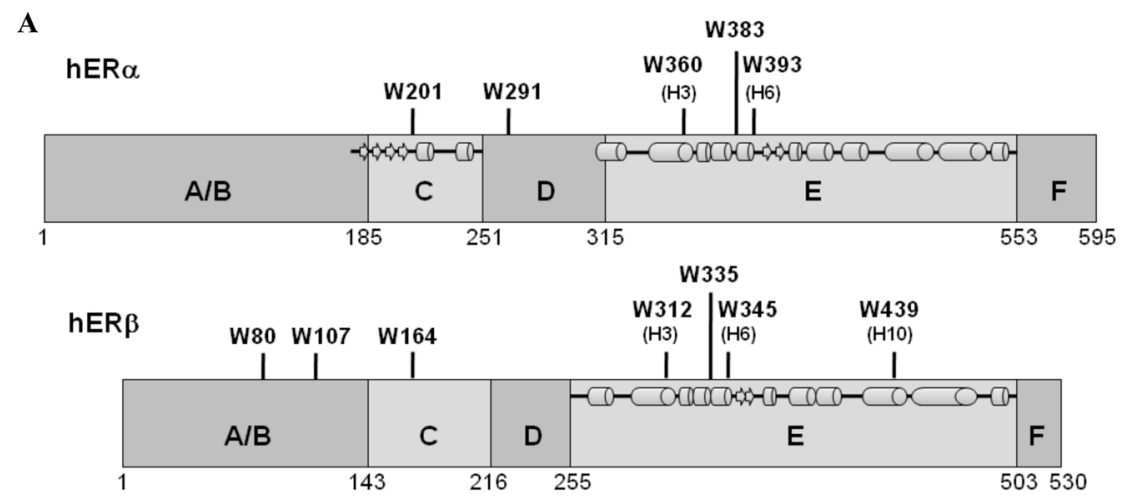

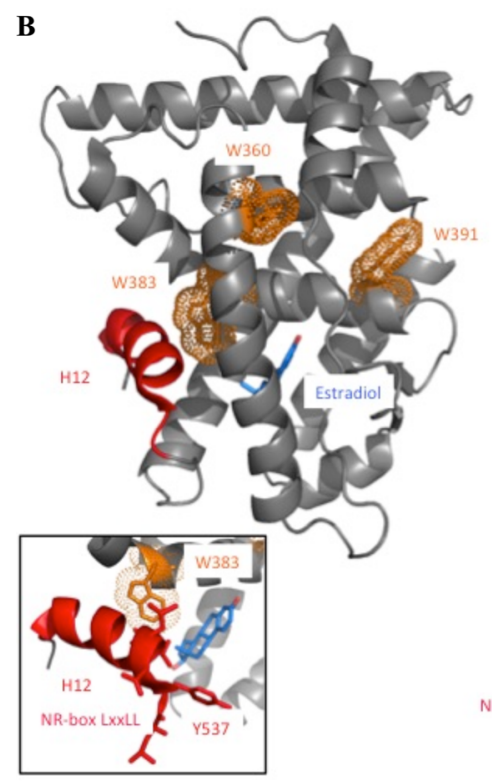

$\mathrm{hER} \alpha(1 \mathrm{G} 50 . \mathrm{pdb})$

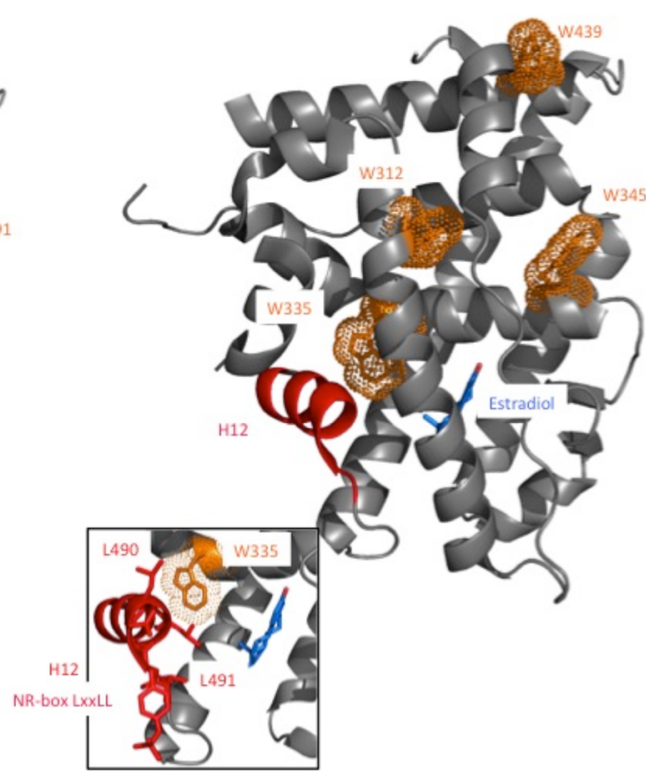

hER $\beta$ (3OLL.pdb)

Figure 4. Positions of tryptophan residues within the hER $\alpha$ and hER $\beta$ isoforms. (A) The position of the tryptophanyl residues is represented along the simplified primary structure of the two estrogen receptor isoforms. The tryptophanyl residues found in an $\alpha$-helix are shown by the $\alpha$-helix number between parentheses. The secondary structure of the DBD and LBD of hERs is schematically shown: helices are shown as cylinders and $\beta$ strands as arrows. (B) Structure of the DBD of both hERs shown as a gray cartoon. The tryptophanyl residues are highlighted as orange dots and sticks, and helix H12 is shown as a red cartoon. The ligand estradiol is shown as blue sticks. Insets are the close views of the NR-box of H12 LxxLL contacting the tryptophanyl residues W383 in hER $\alpha$ and W335 in hER $\beta$ LBD. The first $\mathrm{x}$ is a tyrosine residue in the LBD of both hERs that can be phosphorylated. Those tryptophanyl residues line the agonist binding pocket. This figure was created with Pymol.

fluorescence emission spectra of tryptophanyl residues were collected at increasing concentrations of acrylamide (data not shown). The corresponding Stern-Volmer plots $\left[F_{0} / F=\right.$ $f([$ acrylamide $])]$ are displayed in Figure 5. Within the used acrylamide concentration range, the Stern-Volmer plots are linear, indicating that the observed quenching occurs mainly via a dynamic process. Regardless of the rhER and $\mathrm{KCl}$ concentrations, every tryptophanyl residue is quenched by acrylamide. Table 3 displays the $K_{\mathrm{SV}}$ values calculated from the slope of the curves (see eq 5). From the time-resolved fluorescence experiments, the decay curves have been analyzed by using a three-exponential model. The average lifetime $\langle\tau\rangle$, 
A
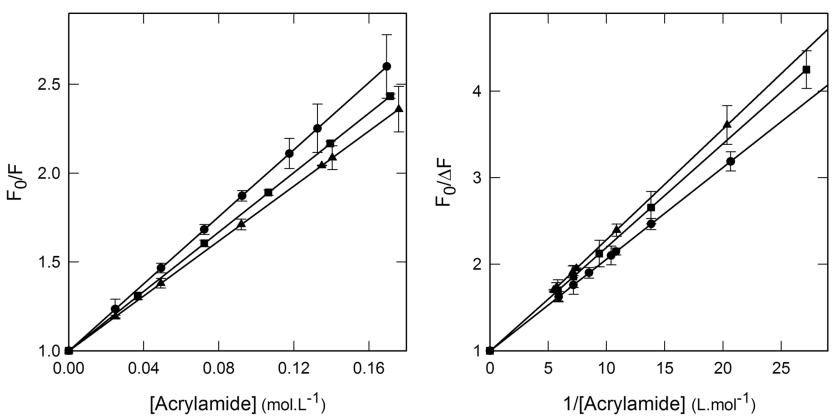

B
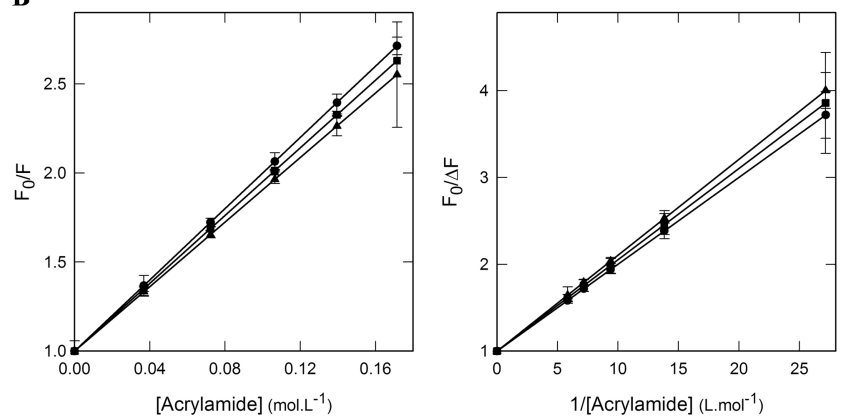

Figure 5. Fluorescence quenching of rhERs by acrylamide as a function of $\mathrm{KCl}$ concentration: (A) $\operatorname{rhER} \alpha$ and (B) $\operatorname{rhER} \beta$. Symbols:

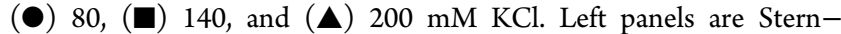
Volmer plots $\left[F_{0} / F=f([\right.$ acrylamide $\left.])\right]$. Right panels are Lehrer plots $\left[F_{0} / \Delta F=f(1 /[\right.$ acrylamide $\left.])\right]$. Experimental conditions are $\mathrm{pH} 7.5$ and $10{ }^{\circ} \mathrm{C}$

Table 3. Recovered Fluorescence Quenching Parameters of rhERs by Acrylamide as a Function of $\mathrm{KCl}$ Concentration ${ }^{a}$

\begin{tabular}{|c|c|c|c|c|}
\hline \multirow[b]{2}{*}{$\begin{array}{l}{[\mathrm{KCl}]} \\
(\mathrm{mM})\end{array}$} & \multicolumn{2}{|c|}{$\operatorname{rhER} \alpha$} & \multicolumn{2}{|c|}{$\operatorname{rhER} \beta$} \\
\hline & $\begin{array}{c}K_{\mathrm{SV}} \\
\left(\mathrm{mol}^{-1} \mathrm{~L}\right)\end{array}$ & $\left(\mathrm{mol}^{-1} \mathrm{~L} \mathrm{~s}^{-1}\right)$ & $\begin{array}{c}K_{\text {SV }} \\
\left(\mathrm{mol}^{-1} \mathrm{~L}\right)\end{array}$ & $\begin{array}{c}k_{\mathrm{q}} \\
\left(\mathrm{mol}^{-1} \mathrm{~L} \mathrm{~s}^{-1}\right)\end{array}$ \\
\hline 80 & $9.4 \pm 0.3$ & $1.72 \times 10^{9}$ & $10.0 \pm 0.3$ & $1.82 \times 10^{9}$ \\
\hline 140 & $8.5 \pm 0.2$ & $1.56 \times 10^{9}$ & $9.5 \pm 0.5$ & $1.73 \times 10^{9}$ \\
\hline 200 & $7.8 \pm 0.2$ & $1.43 \times 10^{9}$ & $9.0 \pm 0.3$ & $1.64 \times 10^{9}$ \\
\hline
\end{tabular}

${ }^{a}$ Experiments were performed at $10 \pm 2{ }^{\circ} \mathrm{C}$ in $10 \mathrm{mM}$ Tris- $\mathrm{HCl}(\mathrm{pH}$ 7.5), $0.1 \mathrm{mM}$ EDTA, $1 \mathrm{mM}$ DTT, and $10 \%$ glycerol. Abbreviations: $K_{\mathrm{SV}}$, Stern-Volmer constant; $k_{\mathrm{q}}$, bimolecular collisional rate constant calculated by using an average lifetime values $(\langle\tau\rangle)$ of $5.45 \mathrm{~ns}$ for $\operatorname{rhER} \alpha$ and $5.48 \mathrm{~ns}$ for $\operatorname{rhER} \beta$.

calculated from eq 8 , has been used to determine the collisional rate constant between acrylamide and tryptophan residues. Whatever the rhER isoform used, the collisional rate constant decreases as the salt concentration increases, indicating that the dynamic accessibility of tryptophan residues is reduced at high salt concentration. Furthermore, the dynamic accessibility of tryptophanyl residues inside $\operatorname{rhER} \alpha$ is slightly lower than that of $\operatorname{rhER} \beta$, indicating that the latter exhibits a less constrained conformation.

Effect of Ligand Binding on rhER Flexibility. Previous studies have reported that the LBD structural plasticity allows the binding of various steroid ligands. ${ }^{42,43}$ Among them, three categories of steroid ligands, called agonists, antagonists, and SERMs, induce upon binding distinct conformational changes such as the repositioning of helix $12 .^{32,44}$ The orientation of this helix modulates coactivator binding. ${ }^{22,23}$
This study included fluorescence quenching and timeresolved fluorescence experiments to investigate the effect of agonists (E2 and DES) and SERMs (4-OHT and RAL) on the entire protein flexibility through the measurement of the dynamic accessibility of tryptophanyl residues. This work has been performed in the presence of $140 \mathrm{mM} \mathrm{KCl}$. As shown in Figure 6, in absence or presence of ligand, all the fluorescent

$\mathbf{A}$
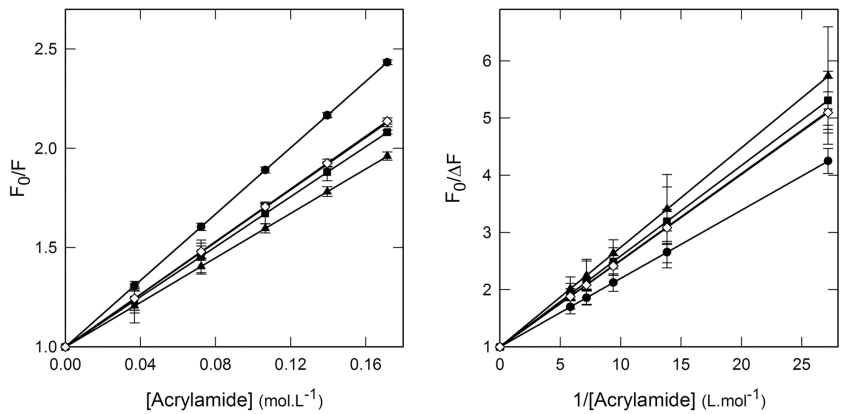

B
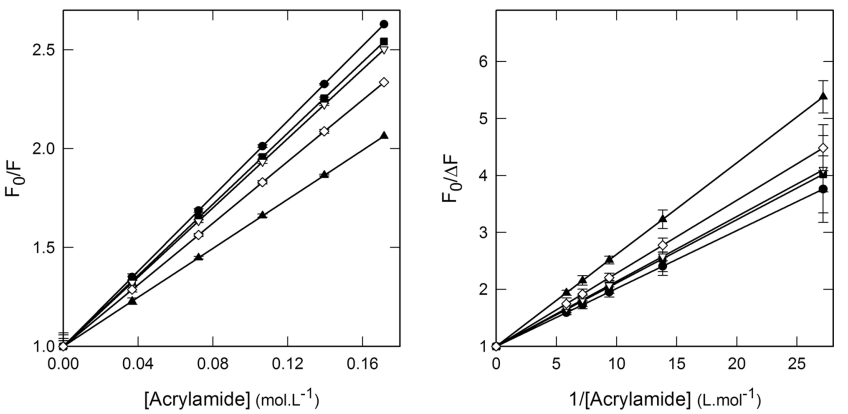

Figure 6. Fluorescence quenching of rhERs by acrylamide in the presence or absence of ligand: (A) $\operatorname{rhER} \alpha$ and (B) $\operatorname{rhER} \beta$. Symbols: $(\bullet)$ no ligand, $(\boldsymbol{\Delta})$ E2, $(\boldsymbol{\square})$ DES, $(\nabla)$ 4-OHT, and $(\diamond)$ RAL. Left panels are Stern-Volmer plots $\left[F_{0} / F=f([\right.$ acrylamide $\left.])\right]$. Right panels are Lehrer plots $\left[F_{0} / \Delta F=f(1 /\right.$ [acrylamide $\left.\left.]\right)\right]$. Experimental conditions: $140 \mathrm{mM} \mathrm{KCl}, \mathrm{pH} 7.5$, and $10{ }^{\circ} \mathrm{C}$.

tryptophanyl residues are accessible and the observed quenching is mostly dynamic in nature. Table 4 displays the $K_{\mathrm{SV}}$ and $k_{\mathrm{q}}$ values obtained for both rhERs, complexed to ligands or not. In the presence of ligands, the $k_{\mathrm{q}}$ values are lower than that observed in the absence of ligand. This finding indicates that the dynamic accessibility of tryptophanyl residues within the hERs is reduced upon ligand binding. Besides, regardless of the complexation state and the bound ligand, $\operatorname{rhER} \beta$ is less constrained than $\operatorname{rhER} \alpha$. Furthermore, no specific effect associated with a particular ligand category has been observed on the flexibility of rhERs. Interestingly, our structural analysis evidenced that $\operatorname{hER} \alpha \operatorname{Trp} 383$ and $\operatorname{hER} \beta \operatorname{Trp} 335$ are gatekeeper residues that distinguish active conformations (agonist-bound) from inactive conformations (apo or antagonist/SERM-bound conformations). Indeed, those tryptophanyl residues are quenched upon agonist binding as they closely interact with activation helix H12 (Figure 4B). Agonist binding promotes the proper positioning of helix $\mathrm{H} 12$ through the NRbox association. NR-box is a consensus LxxLL motif, where $x$ can be any amino acid residue (see insets in Figure 4B, left and right). Agonist binding triggers adequate positioning of helix $\mathrm{H} 12$ to promote a hydrophobic groove at the surface of LBD where the coactivator can thus bind. 
Table 4. Recovered Fluorescence Quenching Parameters of Liganded rhERs by Acrylamide ${ }^{a}$

\begin{tabular}{|c|c|c|c|c|c|c|}
\hline \multirow[b]{2}{*}{ ligand } & \multicolumn{3}{|c|}{$\operatorname{rhER} \alpha$} & \multicolumn{3}{|c|}{$\operatorname{rhER} \beta$} \\
\hline & $K_{\mathrm{SV}}\left(\mathrm{mol}^{-1} \mathrm{~L}\right)$ & $\langle\tau\rangle(\mathrm{ns})\left(\chi^{2}\right)$ & $k_{\mathrm{q}}\left(\mathrm{mol}^{-1} \mathrm{~L} \mathrm{~s}^{-1}\right)$ & $K_{\mathrm{SV}}\left(\mathrm{mol}^{-1} \mathrm{~L}\right)$ & $\langle\tau\rangle(\mathrm{ns})\left(\chi^{2}\right)$ & $k_{\mathrm{q}}\left(\mathrm{mol}^{-1} \mathrm{~L} \mathrm{~s}^{-1}\right)$ \\
\hline none & $8.5 \pm 0.2$ & $5.45(1.06)$ & $1.56 \times 10^{9}$ & $9.5 \pm 0.5$ & $5.48(1.04)$ & $1.73 \times 10^{9}$ \\
\hline $\mathrm{E} 2$ & $6.3 \pm 0.4$ & $5.74(0.98)$ & $1.10 \times 10^{9}$ & $9.0 \pm 0.8$ & $5.52(1.18)$ & $1.63 \times 10^{9}$ \\
\hline DES & $5.6 \pm 0.4$ & $5.93(1.04)$ & $0.94 \times 10^{9}$ & $6.2 \pm 0.3$ & $5.95(1.12)$ & $1.04 \times 10^{9}$ \\
\hline 4-OHT & $6.6 \pm 0.2$ & $5.99(1.17)$ & $1.10 \times 10^{9}$ & $8.4 \pm 0.3$ & $5.26(1.19)$ & $1.60 \times 10^{9}$ \\
\hline RAL & $6.2 \pm 0.6$ & $5.60(1.13)$ & $1.11 \times 10^{9}$ & $7.8 \pm 0.3$ & $5.58(1.18)$ & $1.40 \times 10^{9}$ \\
\hline
\end{tabular}

\section{DISCUSSION}

Regulation of gene expression by estrogen receptors involves successive events such as estrogen binding, release of ERs from inactive complexes, binding of dimeric ERs to EREs located in the promoters of ER-regulated genes, and recruitment of coregulators. ERs may also regulate the expression of target genes by binding to DNA sequences as a heterologous dimer formed with other nuclear transcriptional factors. Besides these genomic effects, ERs are involved in the nongenomic actions of estrogens associated with rapid signal transduction. These distinct estrogen-mediated biological functions, occurring in distinct cellular compartments, imply that ERs exist under different forms within these compartments (nucleus, cytosol, mitochondria, and/or cell membrane). Today, two isoforms of the human estrogen receptor have been identified, hER $\alpha$ and $\operatorname{hER} \beta$. These two hERs, when expressed in the same cell type or organ, exhibit distinct abundances depending on the physiological and/or developmental states and different spliced isoforms. Additionally, these two hERs can display not only a tissue-specific expression but also an estrogen-mediated specific biological function within the tissue. Expressed together, they preferentially form heterodimers, ${ }^{45}$ which, as a consequence of their reduced efficiency in recruiting coactivators, ${ }^{46}$ show a transcriptional activity lower than that of the hER $\alpha$ homodimer. In MCF-7 and HeLa cells, it is fairly well stated that hER $\alpha$ accumulates in the nucleus even in the absence of ligand, and some nuclear punctuate patterns containing the receptor appear following hormonal stimulation. ${ }^{14-16}$ As our understanding of the factors that regulate in particular hER intracellular trafficking and assembly within large complexes mainly relies on our knowledge of the physicochemical features of hERs observed in vitro, we studied the stability and flexibility of these two phosphorylated purified full-length receptors, $\mathrm{hER} \alpha$ and hER $\beta$.

As previously reported, at low salt concentrations, hER $\alpha$ and hER $\beta$ strongly interact with ERE consensus or degenerated sequences; the specificity of these complexes is enhanced by increasing salt concentrations. ${ }^{36,37,39}$ Formation of the complex between hERs and $\mathrm{ERE}_{\mathrm{cs}}$ is little affected by salt concentration. Actually, between 80 and $200 \mathrm{mM} \mathrm{KCl}$, the $K_{\mathrm{D}}$ value of these $\mathrm{hER}-\mathrm{ERE}_{\mathrm{cs}}$ complexes remains in the nanomolar range $(<10$ $\mathrm{nM})$. The effect of salt on formation of the complex between hERs and $r t v t g E R E$ is more pronounced: at $200 \mathrm{mM} \mathrm{KCl}$, the $K_{\mathrm{D}}$ value of this complex is $>40 \mathrm{nM}$. This salt effect well matches the stabilization of hER-ERE complexes by direct and water-mediated hydrogen bonds. ${ }^{18,47}$ Indeed, it has been shown that the interaction between hER residues and ERE phosphate groups requires more water molecules, i.e., more watermediated $\mathrm{H}$ bonds for an imperfect ERE than for the $\mathrm{ERE}_{\mathrm{cs}}{ }^{47}$ Additionally, regardless of the $\mathrm{KCl}$ concentration, $\mathrm{hER} \alpha$ exhibits a slightly higher affinity for both $\mathrm{ERE}_{\mathrm{cs}}$ and $r t v t g E R E$ as compared to that of hER $\beta$. As the highest hER $\alpha$ affinity for ERE cannot be explained by Newtonian attraction between ER and DNA ( $\mathrm{hER} \alpha$ being less positively charged at $\mathrm{pH} 7.5$ than $\mathrm{hER} \beta$ ), this difference in affinity can be assigned to a constrained DNA conformation within hER-ERE complexes. Actually, ERE undergoes a bending upon $\mathrm{hER} \alpha$ complexation, whereas little constraint was observed with hER $\beta .^{48}$ Besides, it was shown that both $\operatorname{hER} \alpha$ and $\operatorname{hER} \beta$ interact with the same nucleotides of $\mathrm{ERE}_{\mathrm{cs}}{ }^{49}$ Hence, the ERE bending, specifically induced by the binding to $\mathrm{hER} \alpha$, might arise from a restricted protein flexibility. From the fluorescence quenching experiments presented here, it appears that all fluorescent tryptophanyl residues exhibit a homogeneous dynamic accessibility regardless of their localization in both hERs, and more importantly, it appears that $\mathrm{hER} \alpha$ flexibility is lower than that of $\operatorname{hER} \beta$. This result agrees well with the observed ERE bending within the hER $\alpha$-ERE complex and with crystallographic data. Actually, structural studies evidence, in both LBDs of ERs, that flexibility is driven by equilibrium between the agonist-bound active conformation and antagonist-bound inactive conformation and fluctuates upon ligand binding. Notably, the fact that hER $\alpha \nu$ ever crystallizes in the apo form evidences its intrinsic flexibility, the latter being enhanced in the absence of ligand. ${ }^{29}$ Similarly, the LBD of hER $\beta$ shows remarkable flexibility in light of the different positions adopted by helix H12, as well as regarding the missing electronic density at the C-terminus of helix $\mathrm{H} 11$ in the crystal forms of E2-ER $\beta$ (PDB entry 3oll) and 4-OHT-ER $\beta$ (PDB entry 2fsz) complexes. As previously shown with $\mathrm{hER} \alpha$, a $\mathrm{KCl}$ concentration increase, within physiological range, leads to restricted fluctuations within the $\operatorname{hER} \beta$ protein. ${ }^{36}$ Increasing the salt concentration also has consequences for hER thermal stability, this effect being more pronounced, mainly at low salt concentrations, for $\mathrm{hER} \alpha$. This differential salt dependence well matches their respective electric charge. Moreover, the thermal unfolding process of both hERs reveals the existence of an intermediate state as already reported by far-UV circular dichroism spectroscopy. ${ }^{50,51}$ Because this partially unfolded conformation is observed at physiological temperature, it must be relevant in the cell physiological and physicochemical context. One may infer that any variation in ion flux within a given subcellular compartment must displace the hER folding equilibrium with consequences for both conformational stability and flexibility of hERs.

Upon hormone binding, estrogen receptors undergo conformational changes essential for their transcriptional activity. However, it has been reported that binding of the ER to ERE is not systematically dependent on ligand binding. ${ }^{37,52}$ Thus, ligand-dependent transactivation of ERs arises from ligand-induced conformational changes, which are decisive for the recruitment of coregulators. Though it has been assumed for a long time that the full-length hER and the 
isolated LBD domain adopt similar conformational changes upon ligand binding, interdomain interactions are now thought to play a significant role in the recruitment of coregulators because a particular ligand may induce conformational changes that are not restricted to the LBD. ${ }^{53}$ It has been previously reported that the two hERs undergo distinct conformational changes and conformational stabilities as a result of E2 and 4OHT binding. Both ligands affect the conformation of $\operatorname{hER} \alpha$, but only E2 increases its thermal stability. Inversely, both ligands enhance the thermal stability of hER $\beta$, whereas only E2 affects its conformation. ${ }^{54,55}$ Our results, obtained from combined fluorescence quenching and time-resolved data, show that the flexibility of both hERs is decreased upon hormone binding regardless of the ligand used. It is observed that flexibility changes decrease in the order E2 $\sim$ RAL $\sim 4$ $\mathrm{OHT}>\mathrm{DES}$ for $\mathrm{hER} \alpha$ and E2-4-OHT $>\mathrm{RAL}>\mathrm{DES}$ for hER $\beta$. These results show that E2 and 4-OHT exert similar effects on the flexibility of both hERs and that DES is the ligand that reduces the protein conformational flexibility the most. Agonist as well as antagonist binding to full-length hERs induces conformational changes with distinct flexibilities. Protein flexibility and ligand categories (agonist, antagonist, or SERM) cannot be linked. The total interaction energies computed for E2, DES, 4-OHT, and RAL in hER $\alpha$ and in $\mathrm{hER} \beta$ are in total agreement with the decrease in flexibility observed experimentally. In both isotypes, DES is the best ligand as compared to others as the potential energy is the lowest (see Table 5). Structural analysis evidenced that lateral ethyl groups

Table 5. Total Potential Energies Computed for Crystal and in Silico Complexes ${ }^{a}$

\begin{tabular}{lcc} 
& \multicolumn{2}{c}{ total potential energy $\left(\mathrm{kcal} \mathrm{mol}^{-1}\right)$} \\
\cline { 2 - 3 } ligand & $\operatorname{rhER} \alpha$ & $\operatorname{rhER} \beta$ \\
E2 & -21924 & -18471 \\
DES & -22426 & -20436 \\
4-OHT & -20935 & -20374 \\
RAL & -19429 & -18639
\end{tabular}

${ }^{a}$ The values in italics refer to those of complexes coming from our docking studies; the others were computed from crystal complexes.

of DES involve additional binding in hER $\alpha$ with Trp383 of helix 5 and Phe425 and Leu540 of the NR-box. These residues, strictly conserved in $\operatorname{hER} \beta$ as $\operatorname{Trp} 335$, Phe377, and Leu490, respectively, reinforce the positioning of ligand and could contribute to freezing the H12 helix, which has been shown to be critical for hER $\alpha$ stability and flexibility (Figure 7).

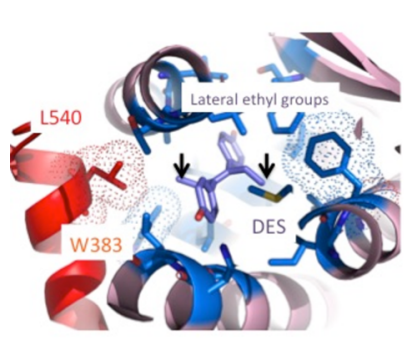

hER $\alpha$ (3erd.pdb)

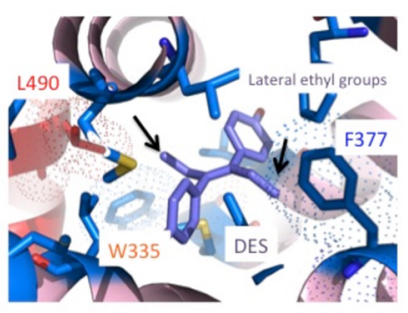

hER $\beta$ (docking)
Figure 7. Close view of DES in the binding pocket of hER $\alpha$ (left) and $\operatorname{hER} \beta$ (right). The residues that are particularly involved in the interaction with the lateral ethyl groups, shown with black arrows, are labeled sticks.

\section{CONCLUSION}

Consistent with our study and previous reports, the structural and energetic features, as determined from full-length estrogen receptors, likely constitute key factors of the fate of hERs in the cells. hER flexibility, stability, and the resulting conformational states must mediate the protein-protein and protein-DNA interactions and ultimately, by modulation of the hERs, binding status and their subcellular localization. From the thermodynamic side, the cellular signaling mechanisms may allow the system enthalpy to vanish. Finally, the relevance of in vitro measurements for investigating the cellular behavior of transcriptional factors is demonstrated even though linear extrapolations from in vitro to in vivo experiments might be hazardous. We propose that the distinct behaviors exhibited by the hERs, evidenced in this study, are functionally relevant for warranting their respective activities within distinct intracellular environments.

\section{ASSOCIATED CONTENT}

\section{S Supporting Information}

Three figures with legends. The Supporting Information is available free of charge on the ACS Publications website at DOI: 10.1021 /acs.biochem.5b00026.

\section{AUTHOR INFORMATION}

\section{Corresponding Author}

*Telephone: 33297017 135. Fax: 33297017 071. E-mail: letilly@univ-ubs.fr.

\section{Funding}

This work was supported by Le Comité du Morbihan de la Ligue Nationale Contre le Cancer and le Ministère de l'Enseignement Supérieur et de la Recherche de France.

\section{Notes}

The authors declare no competing financial interest.

\section{ACKNOWLEDGMENTS}

We thank Xavier Lagrave for his help in fluorescence lifetime measurements performed at Horiba-Jobin-Yvon (Longjumeau, France) and Dr. Odile Lorillon-Mülner and Pr. Catherine A. Royer for their scientific discussions.

\section{ABBREVIATIONS}

E2, $17 \beta$-estradiol; ER, estrogen receptor; ERE, estrogen response element; $\mathrm{LBD}$, ligand binding domain; DBD, DNA binding domain; $\mathrm{ERE}_{\mathrm{cs}}$, consensus estrogen response element; rhER, recombinant human estrogen receptor; $T_{\mathrm{M}}$, melting temperature; MCF-7, Michigan Cancer Foundation-7 (human breast adenocarcinoma cell line); $\mathrm{CHO}$, Chinese hamster ovary; $\mathrm{AF}-1$ and $\mathrm{AF}-2$, transactivation functions 1 and 2, respectively; RAL, raloxifene; DES, diethylstilbestrol; 4-OHT, 4-hydroxytamoxifen; SERMs, selective ER modulators; $r t v t g E R E$, ERE found in the intergenic region of the rainbow trout vitellogenin gene; $\mathrm{NR}$, nuclear receptor.

\section{REFERENCES}

(1) Nilsson, S., and Gustafsson, J. A. (2002) Biological role of estrogen and estrogen receptors. Crit. Rev. Biochem. Mol. Biol. 37, 128.

(2) O’Lone, R., Frith, M. C., Karlsson, E. K., and Hansen, U. (2004) Genomic targets of nuclear estrogen receptors. Mol. Endocrinol. 18, $1859-1875$. 
(3) DeNardo, D. G., Kim, H. T., Hilsenbeck, S., Cuba, V., Tsimelzon, A., and Brown, P. H. (2005) Global gene expression analysis of estrogen receptor transcription factor cross talk in breast cancer: Identification of estrogen-induced/activator protein-1-dependent genes. Mol. Endocrinol. 19, 362-378.

(4) Bruce, M. C., McAllister, D., and Murphy, L. C. (2014) The kinome associated with estrogen receptor-positive status in human breast cancer. Endocr-Relat. Cancer 21, R357-R370.

(5) Green, S., Walter, P., Greene, G., Krust, A., Goffin, C., Jensen, E., Scrace, G., Waterfield, M., and Chambon, P. (1986) Cloning of the human oestrogen receptor cDNA. J. Steroid Biochem. Mol. Biol. 24, 7783.

(6) Mosselman, S., Polman, J., and Dijkema, R. (1996) ER/: Identification and characterization of a novel human estrogen receptor. FEBS Lett. 392, 49-53.

(7) Koehler, K. F., Helguero, L. A., Haldosen, L. A., Warner, M., and Gustafsson, J. A. (2005) Reflections on the discovery and significance of estrogen receptor beta. Endocr. Rev. 26, 465-478.

(8) Enmark, E., Pelto-Huikko, M., Grandien, K., Lagercrantz, S., Lagercrantz, J., Fried, G., Nordenskjold, M., and Gustafsson, J. A. (1997) Human estrogen receptor $\beta$-gene structure, chromosomal localization, and expression pattern. J. Clin. Endocrinol. Metab. 82, $4258-4265$.

(9) Cowley, S. M., and Parker, M. G. (1999) A comparison of transcriptional activation by ER $\alpha$ and ER $\beta$. J. Steroid Biochem. Mol. Biol. 69, 165-175.

(10) Hall, J. M., and McDonnell, D. P. (1999) The estrogen receptor $\beta$-isoform (ER $\beta)$ of the human estrogen receptor modulates $\mathrm{ER} \alpha$ transcriptional activity and is a key regulator of the cellular response to estrogens and antiestrogens. Endocrinology 140, 5566-5578.

(11) Zhu, B. T., Han, G. Z., Shim, J. Y., Wen, Y., and Jiang, X. R. (2008) Quantitative structure-activity relationship of various endogenous estrogen metabolites for human estrogen receptor $\alpha$ and $\beta$ subtypes: Insights into the structural determinants favoring a differential subtype binding. Endocrinology 147, 4132-4150.

(12) Katzenellenbogen, B. S., and Katzenellenbogen, J. A. (2000)

Estrogen receptor transcription and transactivation: Estrogen receptor $\alpha$ and estrogen receptor $\beta$ : Regulation by selective estrogen receptor modulators and importance in breast cancer. Breast Cancer Res. 2, $335-344$.

(13) O’Lone, R., Knorr, K., Jaffe, I. Z., Schaffer, M. E., Martini, P. G., Karas, R. H., Bienkowska, J., Mendelsohn, M. E., and Hansen, U. (2007) Estrogen receptors $\alpha$ and $\beta$ mediate distinct pathways of vascular gene expression, including genes involved in mitochondrial electron transport and generation of reactive oxygen species. Mol. Endocrinol. 21, 1281-1296.

(14) Htun, H., Holth, L. T., Walker, D., Davie, J. R., and Hager, G. L. (1999) Direct visualization of the human estrogen receptor $\alpha$ reveals a role for ligand in the nuclear distribution of the receptor. Mol. Biol. Cell 10, 471-486.

(15) Stenoien, D. L., Mancini, M. G., Patel, K., Allegretto, E. A., Smith, C. L., and Mancini, M. A. (2000) Subnuclear trafficking of estrogen receptor- $\alpha$ and steroid receptor coactivator-1. Mol. Endocrinol. 14, 518-534.

(16) Stenoien, D. L., Patel, K., Mancini, M. G., Dutertre, M., Smith, C. L., O'Malley, B. W., and Mancini, M. A. (2001) FRAP reveals that mobility of oestrogen receptor- $\alpha$ is ligand- and proteasome-dependent. Nat. Cell Biol. 3, 15-23.

(17) Chen, J. Q., Russo, P. A., Cooke, C., Russo, I. H., and Russo, J. (2007) ER $\beta$ shifts from mitochondria to nucleus during estrogeninduced neoplastic transformation of human breast epithelial cells and is involved in estrogen-induced synthesis of mitochondrial respiratory chain proteins. Biochim. Biophys. Acta 1773, 1732-1746.

(18) Schwabe, J. W., Chapman, L., Finch, J. T., and Rhodes, D. (1993) The crystal structure of the estrogen receptor DNA-binding domain bound to DNA: How receptors discriminate between their response elements. Cell 75, 567-578.

(19) Gangloff, M., Ruff, M., Eiler, S., Duclaud, S., Wurtz, J. M., and Moras, D. (2001) Crystal structure of a mutant hER $\alpha$ ligand-binding domain reveals key structural features for the mechanism of partial agonism. J. Biol. Chem. 276, 15059-15065.

(20) Möcklinghoff, S., Rose, R., Carraz, M., Visser, A., Ottmann, C., and Brunsveld, L. (2010) Synthesis and crystal structure of a phosphorylated estrogen receptor ligand binding domain. ChemBioChem 11, 2251-2254.

(21) Ylikomi, T., Wurtz, J. M., Syvala, H., Passinen, S., Pekki, A., Haverinen, M., Blauer, M., Tuohimaa, P., and Gronemeyer, H. (1998) Reappraisal of the role of heat shock proteins as regulators of steroid receptor activity. Crit. Rev. Biochem. Mol. Biol. 33, 437-466.

(22) Klinge, C. M. (2000) Estrogen receptor interaction with coactivators and co-repressors. Steroids 65, 227-251.

(23) Hall, J. M., and McDonnell, D. P. (2005) Coregulators in nuclear estrogen receptor action: From concept to therapeutic targeting. Mol. Interventions 5, 343-357.

(24) McKenna, N. J., Lanz, R. B., and O’Malley, B. W. (1999) Nuclear receptor coregulators: Cellular and molecular biology. Endocr. Rev. 20, 321-344.

(25) Tora, L., White, J., Brou, C., Tasset, D., Webster, N., Scheer, E., and Chambon, P. (1989) The human estrogen receptor has two independent nonacidic transcriptional activation functions. Cell 59, 477-487.

(26) Bouter, A., Buisine, N., Le Grand, A., Mouchel, N., Chesnel, F., Le Goff, C., Le Tilly, V., Wolff, J., and Sire, O. (2010) Control of vitellogenin genes expression by sequences derived from transposable elements in rainbow trout. Biochim. Biophys. Acta 1799, 546-554.

(27) Eftink, M. R., and Ghiron, C. A. (1976) Exposure of tryptophanyl residues in proteins. Quantitative determination by fluorescence quenching studies. Biochemistry 15, 672-680.

(28) Eftink, M. R., and Ghiron, C. A. (1977) Exposure of tryptophanyl residues and protein dynamics. Biochemistry 16, 55465551.

(29) Eiler, S., Gangloff, M., Duclaud, S., Moras, D., and Ruff, M. (2001) Overexpression, purification, and crystal structure of native ER $\alpha$ LBD. Protein Expression Purif. 22, 165-173.

(30) Shiau, A. K., Barstad, D., Loria, P. M., Cheng, L., Kushner, P. J., Agard, D. A., and Greene, G. L. (1998) The structural basis of estrogen receptor/coactivator recognition and the antagonism of this interaction by tamoxifen. Cell 95, 927-937.

(31) Shiau, A. K., Barstad, D., Radek, J. T., Meyers, M. J., Nettles, K. W., Katzenellenbogen, B. S., Katzenellenbogen, J. A., Agard, D. A., and Greene, G. L. (2002) Structural characterization of a subtype-selective ligand reveals a novel mode of estrogen receptor antagonism. Nat. Struct. Biol. 9, 359-364.

(32) Brzozowski, A. M., Pike, A. C., Dauter, Z., Hubbard, R. E., Bonn, T., Engstrom, O., Ohman, L., Greene, G. L., Gustafsson, J. A., and Carlquist, M. (1997) Molecular basis of agonism and antagonism in the oestrogen receptor. Nature 389, 753-758.

(33) Brooks, B. R., Brooks, C. L. I., Mackerell, A. D. J., Nilsson, L., Petrella, R. J., et al. (2009) CHARMM: The biomolecular simulation program. J. Comput. Chem. 30, 1545-1614.

(34) Wang, Z., Zhang, X., Shen, P., Loggie, B. W., Chang, Y., and Deuel, T. F. (2006) A variant of estrogen receptor- $\alpha$, hER- $\alpha 36$ : Transduction of estrogen- and antiestrogen-dependent membraneinitiated mitogenic signaling. Proc. Natl. Acad. Sci. U.S.A. 103, 90639068.

(35) Krissinel, E., and Henrick, K. (2004) Secondary-structure matching (SSM), a new tool for fast protein structure alignment in three dimensions. Acta Crystallogr. D60, 2256-2268.

(36) Bouter, A., Le Tilly, V., and Sire, O. (2005) Interplay of flexibility and stability in the control of estrogen receptor activity. Biochemistry 44, 790-798.

(37) Boyer, M., Poujol, N., Margeat, E., and Royer, C. A. (2000) Quantitative characterization of the interaction between purified human estrogen receptor $\alpha$ and DNA using fluorescence anisotropy. Nucleic Acids Res. 28, 2494-2502.

(38) Le Tilly, V., and Royer, C. (1993) Fluorescence anisotropy assays implicate protein-protein interactions in regulating trp repressor DNA binding. Biochemistry 32, 7753-7758. 
(39) Ozers, M. S., Hill, J. J., Ervin, K., Wood, J. R., Nardulli, A. M., Royer, C. A., and Gorski, J. (1997) Equilibrium binding of estrogen receptor with DNA using fluorescence anisotropy. J. Biol. Chem. 272, 30405-30411.

(40) Zargarian, L., Le Tilly, V., Jamin, N., Chaffotte, A., Gabrielsen, O. S., Toma, F., and Alpert, B. (1999) Myb-DNA recognition: Role of tryptophan residues and structural changes of the minimal DNA binding domain of c-Myb. Biochemistry 38, 1921-1929.

(41) Date, M. S., and Dominy, B. N. (2013) Moduling the influence of salt on the hydrophobic effect and protein fold stability. Commun. Comput. Phys. 13, 90-106.

(42) Ruff, M., Gangloff, M., Wurtz, J. M., and Moras, D. (2000) Estrogen receptor transcription and transactivation: Structure-function relationship in DNA- and ligand-binding domains of estrogen receptors. Breast Cancer Res. 2, 353-359.

(43) Nettles, K. W., Bruning, J. B., Gil, G., O’Neill, E. E., Nowak, J., Guo, Y., Kim, Y., DeSombre, E. R., Dilis, R., Hanson, R. N., Joachimiak, A., and Greene, G. L. (2007) Structural plasticity in the oestrogen receptor ligand-binding domain. EMBO Rep. 8, 563-568.

(44) Pike, A. C., Brzozowski, A. M., Hubbard, R. E., Bonn, T., Thorsell, A. G., Engstrom, O., Ljunggren, J., Gustafsson, J. A., and Carlquist, M. (1999) Structure of the ligand-binding domain of oestrogen receptor $\beta$ in the presence of a partial agonist and a full antagonist. EMBO J. 18, 4608-4618.

(45) Cowley, S. M., Hoare, S., Mosselman, S., and Parker, M. G. (1997) Estrogen receptors $\alpha$ and $\beta$ form heterodimers on DNA. J. Biol. Chem. 272, 19858-19862.

(46) Peng, B., Lu, B., Leygue, E., and Murphy, L. C. (2003) Putative functional characteristics of human estrogen receptor- $\beta$ isoforms. J. Mol. Endocrinol. 30, 13-29.

(47) Kosztin, D., Bishop, T. C., and Schulten, K. (1997) Binding of the estrogen receptor to DNA. The role of waters. Biophys. J. 73, 557570.

(48) Vijayanathan, V., Thomas, T. J., Nair, S., Shirahata, A., Gallo, M. A., and Thomas, T. (2006) Bending of the estrogen response element by polyamines and estrogen receptors $\alpha$ and $\beta$. Int. J. Biochem. Cell Biol. 38, 1191-1206.

(49) Yi, P., Driscoll, M. D., Huang, J., Bhagat, S., Hilf, R., Bambara, R. A., and Muyan, M. (2002) The effects of estrogen-responsive elementand ligand-induced structural changes on the recruitment of cofactors and transcriptional responses by $\operatorname{ER} \alpha$ and $\operatorname{ER} \beta$. Mol. Endocrinol. 16, 674-693.

(50) Gee, A. C., and Katzenellenbogen, J. A. (2001) Probing conformational changes in the estrogen receptor: Evidence for a partially unfolded intermediate facilitating ligand binding and release. Mol. Endocrinol. 15, 421-428.

(51) Nair, S. K., Thomas, T. J., Greenfield, N. J., Chen, A., He, H., and Thomas, T. (2005) Conformational dynamics of estrogen receptors $\alpha$ and $\beta$ as revealed by intrinsic tryptophan fluorescence and circular dichroism. J. Mol. Endocrinol. 35, 211-223.

(52) Furlow, J. D., Murdoch, F. E., and Gorski, J. (1993) High affinity binding of the estrogen receptor to a DNA response element does not require homodimer formation or estrogen. J. Biol. Chem. 268, 1251912525.

(53) Bapat, A. R., and Frail, D. E. (2003) Full-length estrogen receptor $\alpha$ and its ligand-binding domain adopt different conformations upon binding ligand. J. Steroid Biochem. Mol. Biol. 86, 143-149.

(54) Greenfield, N., Vijayanathan, V., Thomas, T. J., Gallo, M. A., and Thomas, T. (2001) Increase in the stability and helical content of estrogen receptor $\alpha$ in the presence of the estrogen response element: Analysis by circular dichroism spectroscopy. Biochemistry 40, 66466652.

(55) Vijayanathan, V., Greenfield, N. J., Thomas, T. J., Ivanova, M. M., Tyulmenkov, V. V., Klinge, C. M., Gallo, M. A., and Thomas, T. (2007) Effects of estradiol and 4-hydroxytamoxifen on the conformation, thermal stability, and DNA recognition of estrogen receptor $\beta$. Biochem. Cell Biol. 85, 1-10. 